\title{
Knowledge, Practice \& Awareness of Tuberculosis Disease among Medical \& Non-medical Students
}

\author{
Maheen Nafees Khan*, Nida Khan, Ghazfa Anwer and Areeba Akbar
}

Department of Pharmacy, Jinnah University for Women, Karachi, Pakistan

\begin{abstract}
Tuberculosis is a contagious disease caused by the causative agent Mycobacterium tuberculosis. Tuberculosis attacks the lungs, yet can similarly impact distinctive parts of the body. The wellspring of transmission of Tuberculosis is through the air when the TB sufferer coughs or sneezes, and blood transfusion. TB grows slowly, thus the disease often is chronic and needs treatment for upto half $\sim 2$ years, particularly if TB get resistance. 33\% of the world's population is thought to have been contaminated with $M$. tuberculosis, and new diseases happen in around $1 \%$ of the populace every year. Thus, the fundamental goal of this article is to check the knowledge and awareness of contagious disease among medical and non-medical students. For this purpose, a survey was carried out among the therapeutic and non-restorative understudies. Total of 100 survey forms were distributed by 3 students in different departments of university that include: Pharmacy (30\%), Microbiology (10\%), Biochemistry $(6 \%)$, Biotechnology $(15 \%)$, BBA (11\%), Commerce (12\%), English (10\%), Computer science $(6 \%)$. The survey took around 30 days. An agreeable reaction got from the students. This study revealed that the students overall have good knowledge regarding TB. The knowledge was analysed after determining various components for assessing the knowledge these include general information about TB, TB is an infectious disease, mode of transmission of TB, causes of $\mathrm{TB}$, treatment and duration of treatment. Majority of respondents was aware to give correct answer and showed the reason of having good knowledge The gap is there in knowledge score when compared with various age groups and medical and non-medical students, there is clear findings that difference in knowledge is reason of medical background but in turn it is alarming situation because the respondents in our community is divided on various educational programs so here should be awareness and knowledge based programs be there for enhancing overall knowledge that in turn reducing the burden of such contagious diseases.
\end{abstract}

Keywords: M. tuberculosis; Tuberculosis; Resistance; Microbiology

\section{Introduction}

Tuberculosis, or TB, in the past additionally called phthisis, phthisis pulmonalis, is an across the board, and irresistible illness created by different strains of mycobacteria, generally M. tuberculosis [1]. Tuberculosis normally assaults the lungs, yet can likewise influence different parts of the body. It is spread through the air when individuals who have a dynamic TB disease cough, wheeze, or generally transmit respiratory liquids through the air [2]. Many people who are presented to TB never create indications on the grounds that the microbes can live in an idle structure in the body. Be that as it may, if the invulnerable framework debilitates, for example, in individuals with HIV or elderly grown-ups, TB microorganisms can get to be dynamic. In their dynamic state, TB microbes cause passing of tissue in the organs they contaminate. Dynamic TB sickness can be lethal if left untreated [3]. The side effects of dynamic TB incorporate the accompanying: Coughing, occasionally with bodily fluid or blood, Chills, Weariness, Fever, Loss of weight, Loss of hunger, Night sweats. Tuberculosis for the most part influences the lungs, yet can likewise influence different parts of the body. At the point when TB happens outside of the lungs, the indications can fluctuate likewise. Without treatment, TB can spread to different parts of the body through the circulatory system: TB infecting the bones can prompt spinal pain and joint obliteration, TB infecting the mind can bring about meningitis, TB contaminating the liver and kidneys can weaken their waste filtration capacities and lead to blood in the urine [4]. 33\% of the world's population is thought to have been contaminated with $M$. tuberculosis, and new diseases happen in around $1 \%$ of the populace every year. In 2007, an expected 13.7 million ceaseless cases were dynamic allinclusive while in 2013, an expected 9 million new cases happened. In 2013 there were somewhere around 1.3 and 1.5 million related deaths, most of which happened in creating nations [5]. There is minimal reliable epidemiological information accessible for Pakistan, in spite of the fact that TB is thought to be a noteworthy reason for sick health. The yearly frequency rate of irresistible TB cases is assessed to be between $85-100 / 100,000$ persons. Yearly around 120,000 new TB cases are being added to the current number of irresistible people. A few territories in the nation have much higher figures, for example, Northern Pakistan where a predominance figure of 554/100,000 cases was observed [6]. The most widely recognized symptomatic test for TB is a skin test, however, different tests are accessible to analyse TB. Blood tests, chest $\mathrm{X}$-rays and sputum tests can all be utilized to test for the vicinity of TB microorganisms, and may be utilized nearby a skin test [7]. Prevention depends on screening projects and vaccination. In those parts of the world where the infection is normal, the World Health Organization prescribes that new-born children get an immunization called BCG (Bacille Calmette-Guérin). BCG is genuinely viable in shielding little kids from extreme TB complexities [8]. Individuals with latent TB may require only one sort of TB anti-microbial, though individuals with dynamic TB (especially MDR-TB) will frequently oblige a medicine of different medications. Antibiotic resistance is a growing problem in multiple drug-resistant tuberculosis (MDR-TB) infections. Anti-

${ }^{*}$ Corresponding author: Maheen Nafees Khan, Faculty of Pharmacy, Jinnah University for Women, Karachi, Pakistan, Tel: 00923002621917; E-mail: mahadua39@gmail.com

Received October 03, 2017; Accepted November 15, 2017; Published November 27, 2017

Citation: Khan MN, Khan N, Anwer G, Akbar A (2017) Knowledge, Practice \& Awareness of Tuberculosis Disease among Medical \& Non-medical Students. J Bioequiv Availab 9: 561-564. doi: 10.4172/jbb.1000362

Copyright: @ 2017 Khan MN, et al. This is an open-access article distributed under the terms of the Creative Commons Attribution License, which permits unrestricted use, distribution, and reproduction in any medium, provided the original author and source are credited. 
Citation: Khan MN, Khan N, Anwer G, Akbar A (2017) Knowledge, Practice \& Awareness of Tuberculosis Disease among Medical \& Non-medical Students. J Bioequiv Availab 9: 561-564. doi: 10.4172/jbb.1000362

microbial is generally needed to be taken for a moderately long time. The standard time span for a course of TB anti-microbial speaks the truth 6 months. The two anti-infection agents most normally utilized are isoniazid and rifampicin. The suggested treatment of new-onset pneumonic tuberculosis, starting 2010, is six months of a blend of antitoxins containing rifampicin, isoniazid, pyrazinamide, and ethambutol for the initial two months, and just rifampicin and isoniazid throughout the previous four months. Where imperviousness to isoniazid is high, ethambutol may be included throughout the previous four months as an option $[9,10]$. Thus, the objective of this study is to determine the knowledge and awareness of contagious disease among medical and non-medical students.

\section{Methodology}

The approach embraced was the distribution of specially designed survey forms. Total of 100 survey forms were distributed by 3 students in different departments of university that include: Pharmacy (30\%), Microbiology (10\%), Biochemistry (6\%), Biotechnology (15\%), BBA (11\%), Commerce (12\%), English (10\%), Computer science (6\%). The survey took around 30 days. An agreeable reaction was got from the students. The vast majority of the students were entirely cooperative regardless of couple of odd cases, half were most certainly not discovered included in TB learning and half affirmed their association. The sole reason for the overview was to aggregate taking after insights, which are in consequent paragraphs.

\section{Results}

The result shown with response rate of $100 \%$ of respondents who were involved in this study. Majority of students 55 (50.0\%) were from age group between 18-20 years, among these respondents 59 (53.6\%) were medical while remaining $51(46.4 \%)$ were non-medical students. As shown in following Table 1.

The knowledge score was analysed by using SPSS v.20, which comprises of various questions, the correct answer was marked as 1 while incorrect answers were coded as 0 , so the over al knowledge score was calculated against age group and medical, non-medical students as shown in Table 2 .

The table shows that response noticeable in age ranges between 21-23 years having good knowledge, similarly it is clear that medical students are dominant with good knowledge regarding TB as compared with that of non-medical students.

The knowledge score related to various age group with comparison of medical and non-medical students is shows in Graph 1. This graphical representation signifies that respondents from age group 2123 years from medical side was very much aware of TB while on other side of non-medical students, it is contrary to finings with medical students. Another important description seen in this graph that nonmedical students have greater percentage of poor knowledge.

In Graph 2 overall study findings showed awareness, prevention and hygiene practice of respondents, that is answered in yes and no, though knowledge or awareness is seen in majority while it is negatively stated about prevention and hygiene.

The overall response of students in various questions concerning TB knowledge is shown in following Table 3 .

The source of information graph (Graph 3) shows respondents overall information resources through which they seek info regarding TB is dominant with Internet about $47 \%$ followed by TV source that accounts overall $37 \%$ (Table 4 ).

\section{Discussion}

This study revealed that the students overall have good knowledge regarding TB. The knowledge was analysed after determining various components for assessing the knowledge these include general information about TB, TB is an infectious disease, mode of transmission of TB, causes of TB, treatment and duration of treatment. Majority of

\begin{tabular}{|c|c|}
\hline Age & $\mathbf{N}(\%)$ \\
\hline $18-20$ & $20(18.2 \%)$ \\
\hline $21-23$ & $77(70.0 \%)$ \\
\hline $24-26$ & $13(11.8 \%)$ \\
\hline
\end{tabular}

Table 1: Respondents Age group.

\begin{tabular}{|c|c|c|c|c|c|}
\hline Knowledge & \multicolumn{3}{|c|}{ Age Group } & \multicolumn{2}{c|}{ Students } \\
\hline & $\mathbf{1 8 - 2 0}$ & $\mathbf{2 1 - 2 3}$ & $\mathbf{2 4 - 2 6}$ & Medical & Non-Medical \\
\hline Good Knowledge & 33 & 40 & 3 & 51 & 25 \\
\hline Poor Knowledge & 22 & 11 & 1 & 8 & 26 \\
\hline
\end{tabular}

Table 2: knowledge Score by Age Group and amongst students.

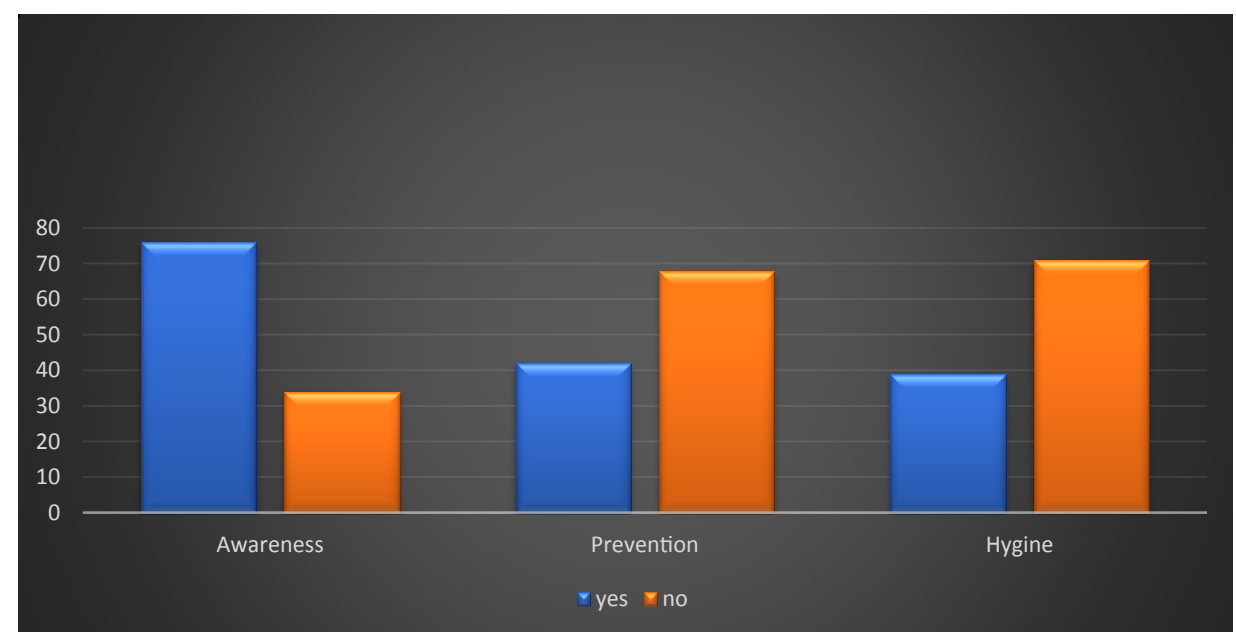

Graph 1: Knowledge score related to various age group with comparison of medical and non-medical students. 
Citation: Khan MN, Khan N, Anwer G, Akbar A (2017) Knowledge, Practice \& Awareness of Tuberculosis Disease among Medical \& Non-medical Students. J Bioequiv Availab 9: 561-564. doi: 10.4172/jbb.1000362

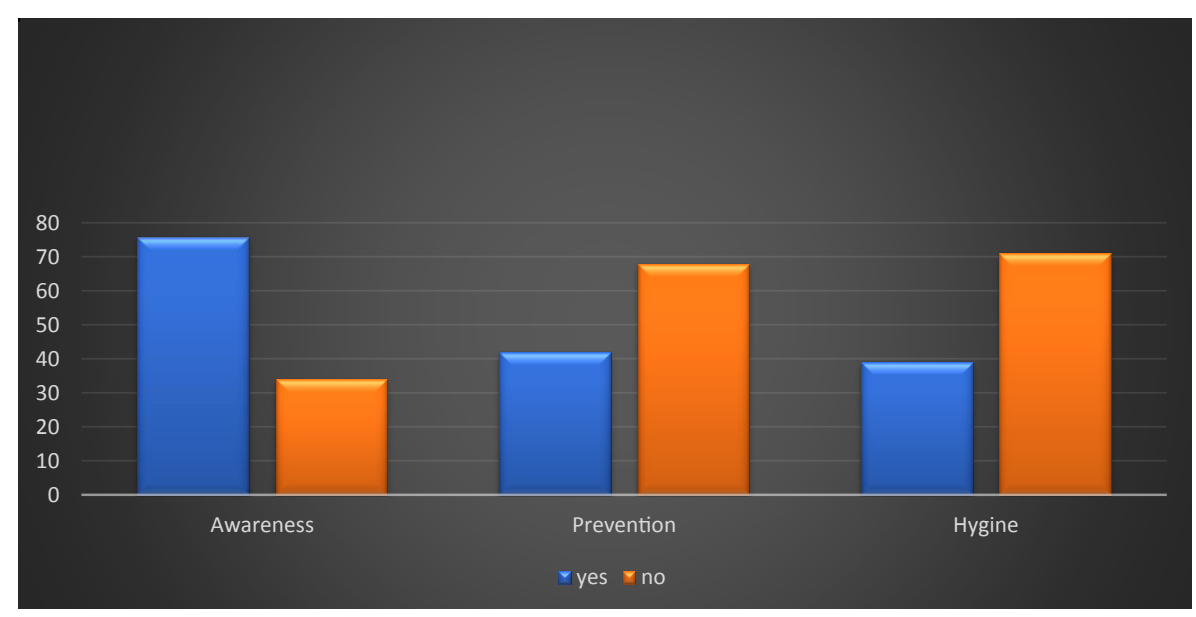

Graph 2: Overall study findings showed awareness, prevention and hygiene practice of respondents.

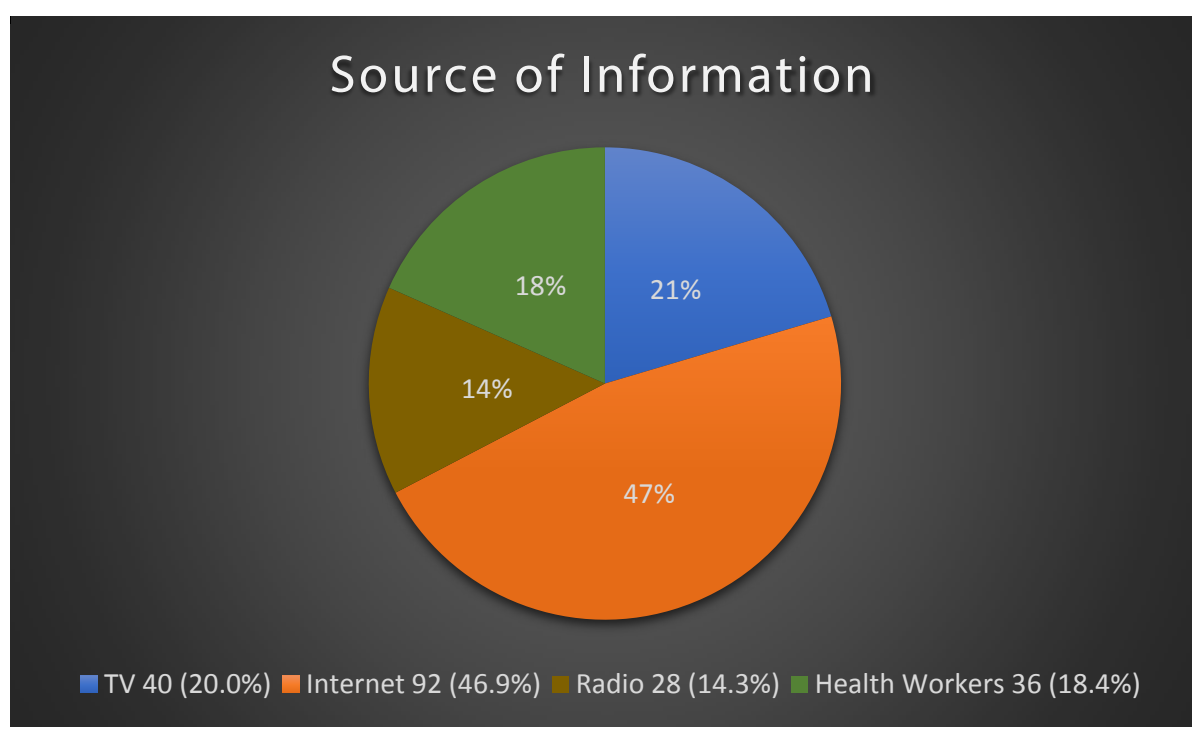

Graph 3: Source of information graph shows respondents overall information resources. More than one responses were allowed in sources.

\begin{tabular}{|c|c|c|}
\hline Questions & Yes (\%) & No (\%) \\
\hline Do you know about disease TB & $91.80 \%$ & $8.20 \%$ \\
\hline Do you know TB is contagious & $58.20 \%$ & $41.80 \%$ \\
\hline Do you know causative agent of TB & $79.10 \%$ & $20.90 \%$ \\
\hline Do you know which is source of transmission of TB & $56.40 \%$ & $43.60 \%$ \\
\hline Do you know about its symptoms & $57.30 \%$ & $42.70 \%$ \\
\hline Do you know treatment option for TB & $54.50 \%$ & $45.50 \%$ \\
\hline Is there vaccine for available for TB & $55.50 \%$ & $44.50 \%$ \\
\hline Is TB treatment is 6 months & $61.80 \%$ & $37.40 \%$ \\
\hline Is TB is curable & $67.30 \%$ & $32.70 \%$ \\
\hline Have you done with its vaccination & $38.20 \%$ & $61.80 \%$ \\
\hline
\end{tabular}

Table 3: The overall response of students in various questions concerning TB knowledge.

respondents was aware to give correct answer and showed the reason of having good knowledge. This is in contrary to the study which states the opposite situation conducted in Malaysia where they have poor knowledge. The knowledge score was consistent to the findings of other studies, which showed that the knowledge about tuberculosis among TB patients was quite high $[11,12]$.

\begin{tabular}{|c|c|c|}
\hline Source of Information & N (\%) & Percent Cases \\
\hline TV & $40(20.0 \%)$ & $36.70 \%$ \\
\hline Internet & $92(46.9 \%)$ & $84.40 \%$ \\
\hline Radio & $28(14.3 \%)$ & $25.70 \%$ \\
\hline Health Workers & $36(18.4 \%)$ & $33.00 \%$ \\
\hline
\end{tabular}

Table 4: Overall information resources through which they seek info regarding TB.

The cause of the disease is main concern while assessing the knowledge of the disease among patients and knowing the cause may increase or decrease the occurrence of disease, among these causes the lack of knowledge was seen in TB cause by bacteria or which is the source of transmission because almost forty eight percent do not know about transmission of a disease, so this can lead to deterioration of disease. These findings are consistent with the study conducted to assess the knowledge about tuberculosis among newly diagnosed TB patients in India [12].

The gap is there in knowledge score when compared with various age groups and medical and non-medical students, there is clear findings that difference in knowledge is reason of medical background 
Citation: Khan MN, Khan N, Anwer G, Akbar A (2017) Knowledge, Practice \& Awareness of Tuberculosis Disease among Medical \& Non-medical Students. J Bioequiv Availab 9: 561-564. doi: 10.4172/jbb.1000362

but in turn it is alarming situation because the respondents in our community is divided on various educational programs so here should be awareness and knowledge based programs be there for enhancing overall knowledge that in turn reducing the burden of such contagious diseases.

Appropriate knowledge is of prime importance for control and prevention of many diseases and tuberculosis. This study concludes that knowledge about tuberculosis among the students is good and highlights the importance for planning designing and applying appropriate programs and interventions to propagate the knowledge and information about tuberculosis in the general population. There is need of more studies and research to assess knowledge and understanding about tuberculosis at higher and community basis. This should only be possible with incorporated efforts by government and non-governmental health organizations, media along with active community participation. In this study, it was found that knowledge about the diagnosis of disease is far better as compared to the knowledge of the cause \& mode of transmission of TB.

\section{Conclusion}

In this study majority of study subjects had good knowledge about cause of tuberculosis, its mode of transmission \& duration of treatment while knowledge regarding the major symptoms of TB was found better among most of the respondents. It is concluded that as knowledge is a key factor for the prevention and control of TB so planning and appropriate health education programs, seminars and interventions regardless to the level of education of population to propagate the knowledge is necessary.

\section{References}

1. Kumar V, Abbas AK, Fausto N, Mitchell RN (2007) Robbins Basic Pathology, 8th edn. Saunders Elsevier 516-522.

2. Konstantinos A (2010) Testing for tuberculosis. Australian Prescriber 33: 12-18.

3. Lisa B, Bernstein M (2015) Understanding Tuberculosis - the Basics. Lung Disease \& Respiratory Health Center.

4. Konstantinos A (2010) Testing for tuberculosis. Australian Prescriber 33: 12-18.

5. World Health Organization (2009) Global tuberculosis control: epidemiology, strategy, financing. WHO report. Geneva, Switzerland: World Health Organization.

6. World Bank Organization (1998) Health, Nutrition and Population Unit, South East Asia Region. World Health Organization.

7. World Health Organization (2010) Global tuberculosis control: WHO Report 2010. Geneva.

8. Lawn SD, Zumla Al (2011) Tuberculosis. Lancet 378: 57-72.

9. Menzies D, Al Jahdali H, Al Otaibi B (2011) Recent developments in treatment of latent tuberculosis infection. Indian J Med Res 133: 257-266.

10. Liam C, Lim K, Wong C, Tang B (1999) Attitudes and knowledge of newly diagnosed tuberculosis patients regarding the disease, and factors affecting treatment compliance. Int J Tuberc Lung Dis 3: 300-309.

11. Hoa NP, Diwan VK, Co NV, Thorson AEK (2004) Knowledge about tuberculosis and its treatment among new pulmonary TB patients in the north and central regions of Vietnam. The Intern $\mathrm{J}$ Tuberculosis and Lung Disease 8: 603-608.

12. Damor R, Singh M, Jankar D, Rathod S, Gosaliya V (2012) Assessment of Knowledge about Tuberculosis among Newly Diagnosed Patients Registered in District Tuberculosis Center, Bhavnagar, Gujarat. Natl J Integr Res Med 43: 29. 